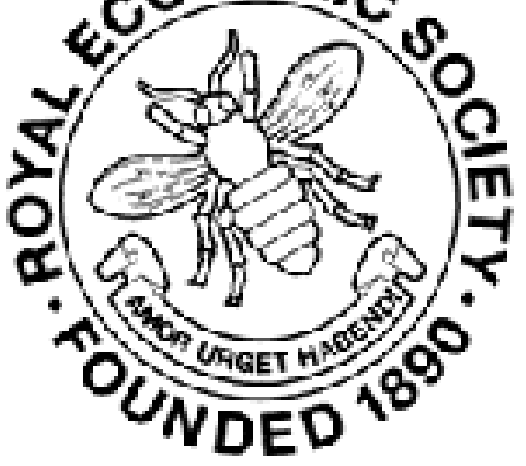

Mortality in Extreme Old Age Author(s): Harald Westergaard

Source: The Economic Journal, Vol. 9, No. 34 (Jun., 1899), pp. 315-322

Published by: Wiley on behalf of the Royal Economic Society

Stable URL: http://www.jstor.org/stable/2956824

Accessed: 27-06-2016 09:20 UTC

Your use of the JSTOR archive indicates your acceptance of the Terms \& Conditions of Use, available at

http://about.jstor.org/terms

JSTOR is a not-for-profit service that helps scholars, researchers, and students discover, use, and build upon a wide range of content in a trusted digital archive. We use information technology and tools to increase productivity and facilitate new forms of scholarship. For more information about JSTOR, please contact support@jstor.org.

Royal Economic Society, Wiley are collaborating with JSTOR to digitize, preserve and extend access to The Economic Journal 
theory of economics might still confer a benefit analogous to that which the mathematical theory of astronomy conferred when it discredited the pernicious pretensions of the astrologers. There are those who think that even of the received economic analysis the most important function is negative. Thus Mr. Leslie Stephen:-

" Political economy, as I venture to think, has been especially valuable in what I have called its negative aspect. It has been more efficient in dispersing sophistries than in constructing permanent theories. Economic writers have exploded many absurd systems. They have so far cleared the way for an application of sounder methods. But the complexity of the problem is so great . . . ."1

The sort of sophistry which has been eradicated from the general field of economics by the received organon finds a still virgin soil in the nooks and corners of which the cultivation requires the implements of mathematics.

The trenchancy of this criticism is not inconsistent with the diffidence which is proper to an inexact science, and the respect which is due to a high authority. For on the one hand, the region of hypothetically abstract theory, to which this polemic is confined, forms the one territory of economics in which issues may be fought out without compromise, there being a right diametrically opposed to the wrong. And on the other hand, it is no discredit to the ablest combatant, when he is unprovided with the proper weapons, to succumb.

F. Y. EDGEWORTH.

\section{Mortality in Extreme Old Age}

In times past longevity was a favourite subject among authors on vital statistics. Curious lists with particulars as to very old persons were drawn up and discussed, and the aspects of longevity under various circumstances traced. Thus the well-known German statistician, Süssmilch, author of the voluminous work Die Göttliche Ordnung, deal at length with this question (1.c. $\$ \$ 81$ seq.). The famous naturalist A. v. Haller, likewise, in his Elementa Physiologia Corporis Humani, deals with longevity generally as well as with " longævitas hominis" before and after the flood, pointing out several causes, as heredity, frugality, or contemplative habits of life. Later on C. W. Hufeland wrote his renowned Makrobiotik (1796), William Barton his Observations on the Probabilities of the Duration of Human Life (1793), and James Easton his Health and Longevity (1799).

A hundred years ago there was thus a series of observations on longevity at hand, which might have led to interesting conclusions, if they had only been correct. Unfortunately this was not the case; many of the most famous records of longevity have been reduced into absurdity, or they have at least lost much of their romantic flavour.

${ }^{1}$ Life of Fawcett, p. 149. 
Some curious instances will be found in a paper by an American author, J. E. Worcester (Remarks on Longevity, \&c., 1833): "In a magazine published at Philadelphia in 1804, it was stated that Samuel Bartrow died at Boothbay, Maine, at the age of 135. But instead of this it appears that a man of the name of Barter died at that place at the age of 105. Several newspapers and journals, in 1823, mentioned the death of a Moor, of the name of Yarrow, at Georgetown, Columbia, at the age of 135 , but it has been found that his age was only about $85 . "$

Undoubtedly several other records of centenarians are tolerably accurate. If we confine ourselves to the comparatively youthful persons of $100-105$ years, we shall find many reliable cases, as that of Sir Moses Montefiore, or of the French naturalist Chevreuil, and even if we go to much higher ages, there is often good evidence, as in the case of the Norwegian Drakenberg (1626-1772), who married when 111 years old, and as a widower of 130 proposed to marry again, though without success. ${ }^{1}$ But these records are neutralised by other more or less doubtful cases, and at the end of the 19th century statistics of longevity are still in a very incomplete condition.

No wonder then that life tables generally take very small notice of extreme old ages. Sometimes they stop abruptly, for instance at 100 years of age, or the rates of mortality in the highest ages of life are not based on observations, but on some fiction, generally that mortality is increasing with age according to a simple mathematical function till all have died out. But probably none of the authors of life tables would look upon this scale of probabilities otherwise than as a conventional fashion of bringing a tale to an end, nor is it of any practical consequence in life assurance or similar matters what are the rates of mortality among very aged persons, the number surviving being so small that it is of nearly no influence on the premiums charged by the life offices what is the law of mortality in this period of life. No wonder therefore that modern statisticians have taken so small notice of this question.

But even if life tables have no great value for business purposes, they may have an intrinsic value, and I hope the following investigation will be found of some interest for students of vital statistics.

If we consult the unadjusted life tables we sometimes find a curious interruption in the general law of mortality. The following table shows the probabilities of dying in the course of a year for males of various ages according to the German and Norwegian life tables 1871-1881.

It will be seen on inspection of these numbers, that the chances of dying within the next year are not increasing according to the German unadjusted table and, from 95 years of age, rather decreasing according to the Norwegian table. The question arises whether this must be ascribed to the defects of the numerical observations or whether there

${ }^{1}$ Dansk Biografisk Lexikon, IV, 1890, pp. 327-8. 


\begin{tabular}{|c|c|c|c|c|}
\hline \multirow[b]{2}{*}{ Age. } & \multicolumn{2}{|c|}{ Germany. } & \multicolumn{2}{|c|}{ Norway. } \\
\hline & Unadjusted table. & Adjusted table. & Unadjusted table. & Adjusted table. \\
\hline $\begin{array}{c}\text { Years. } \\
90 \\
91 \\
92 \\
93 \\
94 \\
95 \\
96 \\
97 \\
98 \\
99 \\
100 \\
101 \\
102 \\
103 \\
104 \\
105\end{array}$ & $\begin{array}{l}0 \cdot 30 \\
0 \cdot 28 \\
0 \cdot 27 \\
0 \cdot 26 \\
0 \cdot 26 \\
0 \cdot 25 \\
0 \cdot 24 \\
0 \cdot 25 \\
0 \cdot 28 \\
0 \cdot 29 \\
0 \cdot 34 \\
= \\
= \\
=\end{array}$ & $\begin{array}{l}0.32 \\
0 \cdot 33 \\
0 \cdot 35 \\
0 \cdot 37 \\
0 \cdot 38 \\
0 \cdot 40 \\
0 \cdot 42 \\
0 \cdot 44 \\
0 \cdot 47 \\
0 \cdot 49 \\
0 \cdot 52 \\
= \\
= \\
- \\
-\end{array}$ & $\begin{array}{l}0 \cdot 23 \\
0 \cdot 24 \\
0 \cdot 24 \\
0 \cdot 27 \\
0 \cdot 28 \\
0 \cdot 33 \\
0 \cdot 31 \\
0 \cdot 26 \\
0 \cdot 30 \\
0 \cdot 24 \\
0 \cdot 15 \\
0 \cdot 15 \\
0 \cdot 10 \\
0 \cdot 05 \\
0 \cdot 13 \\
0 \cdot 15\end{array}$ & $\begin{array}{l}0 \cdot 23 \\
0 \cdot 24 \\
0 \cdot 25 \\
0 \cdot 26 \\
0 \cdot 29 \\
0 \cdot 31 \\
0 \cdot 33 \\
0 \cdot 34 \\
0 \cdot 36 \\
0 \cdot 38 \\
0 \cdot 41 \\
0 \cdot 44 \\
0 \cdot 47 \\
0.51 \\
0.55 \\
1 \cdot 00\end{array}$ \\
\hline
\end{tabular}

is a real influence counteracting the general tendency to an increase in mortality according to age.

It is evident that a person like Drakenberg could hardly have existed if 50 per cent. or more of the old persons alive died every year. Very few persons in a million will reach 100 years of age, but if out of these one half died yearly, only $\frac{1}{1000}$ of the centenarians would reach 110 years, and one out of a million 120. If there are some rare cases of persons with an extraordinary age, the law of mortality must have a form which renders it possible to meet these exceptions every now and then.

But, on the other hand, we cannot rely on the official statistical data without any revision. For instance, if only a few persons were erroneously made 20 years older than they are, we might observe a conspicuous influence on the law of mortality in the very old ages. According to the Norwegian table there will be 33,695 males alive at $70,15,347$ at $80,2,440$ at 90 , and 70 at 100 . Let us now suppose that only 1 per mille of males, 70 years old, was erroneously registered as 90 years old, the number of males of this age would be 2474 instead of 2440; the error would thus be of little consequence. Ten years later there would be about 15 persons alive out of the 34 persons whose age was wrongly registered, and if the mistake is still undiscovered, the number of centenarians will be increased from 70 to 85 . The influence of this apparently insignificant error will thus be constantly greater every year. The probability of dying before a year for a person of 95 years would be nearly unaltered, but for a centenarian it would sink from 41 to 36 per cent., and 5 years later it would be about 30 per cent. instead of 60 per cent. It will thus be necessary to be very careful in order to draw correct conclusions out of such observations.

The Norwegian Central Office of Statistics adopted the good plan 
of revising the observations from the census 1st January, 1891, on aged persons above 95 years of age, with the help of the church registers, and to follow these persons closely through the following 5 years till the end of 1895..$^{1}$ The list has been afterwards carefully revised once more and even if there are possibly still some inaccuracies left, these observations seem trustworthy enough to allow conclusions as to mortality in these ages. ${ }^{2}$

Altogether, 323 persons came under observation, 111 males, 212 females; out of these about $\frac{1}{3}$ gave their age incorrectly. One of them was 12 years younger than according to the census, but on the whole the errors are much more inconsiderable, and the collective result of all the errors is that the average age both of males and females is overstated with only about 10 months. There is even a chance that this difference may be still a little reduced, for there may have been some persons above 95 , but registered by the census as younger, who are therefore not on the list. Still there is evidently a much greater inclination to overstating the age than to giving a smaller age than the real one, so these cases are probably not very numerous.

Generally, in statistical investigations, the year is used as unit of time. In dealing with these observations I have preferred the quarter of a year as unit, the after life-time allotted to these aged persons being so short. Each person has been taken under observation from the first day after January 1st, 1891, when a fresh quarter of a year began, and till the end of the last quarter before December 31st, 1895, if he did not die before; fractions of quarters of a year thus being left out of consideration. If a man is born 1st February, 1790, and is still alive on 31st October, 1895, I have thus taken him under observation from 1st February, 1891, till 31st October, 1895, i.e., 19 quarters of a year.

A quarter of a year has been, under this supposition, commenced altogether 2457 times by the persons observed, viz., 756 by males, 1701 by females, with 82 and 147 cases of death. Out of 100 persons there consequently died 9 before the end of a quarter, viz., 8.6 per cent. of females, 10.8 of males. The difference between the mortality of males and females is not particularly striking, and I have therefore preferred to deal with both sexes combined, in order to secure somewhat larger numbers.

According to these observations about $\frac{1}{3}$ of the aged persons died within a year, but the mortality seems to be decreasing instead of increasing according to age, and the above-mentioned stoppage in the general movement of mortality seems to be evidenced by these observations, few as they are in number.

These observations are, however, open to an objection. Mortality

${ }^{1}$ A similar proceeding has been followed for years by the Swedish Central Office of Statistics.

2 In a contribution to Nationalokkonomisk Tidsskrift I have dealt with these observations before the additional list of corrections was published; the numerical results here given therefore differ a little from what was stated in that article. 


\begin{tabular}{|c|c|c|c|}
\hline Age. & $\begin{array}{c}\text { Numbers alive at the } \\
\text { beginning of a } \\
\text { quarter of a year. }\end{array}$ & Number of deaths. & $\begin{array}{c}\text { Of 100 persons alive, } \\
\text { there died in the course } \\
\text { of a quarter of a year. }\end{array}$ \\
\hline Years. & & & \\
95 & 292 & 33 & 11 \\
96 & 456 & 44 & 10 \\
97 & 458 & 38 & 8 \\
98 & 426 & 47 & 11 \\
99 & 327 & 28 & 9 \\
100 & 205 & 5 & 11 \\
101 & 114 & 6 & \\
102 & 76 & 2 & 6 \\
103 & 46 & 3 & \\
104 & 18 & 0 & \\
105 & 2 & 229 & \\
106 & 2457 & & \\
Total....... & & & \\
\hline
\end{tabular}

in this period of life is evidently rather variable, according to the more or less favourable meteorological character of the year. During the first 4 quarters of a year mortality was 10.37 per cent., in the next 4 quarters $11 \cdot 20$, and then $6.82,6.60$, and 8.70. On the whole the two first years were unfavourable, whereas the rest of the period had a relatively small mortality. But during these five years the persons under observation have grown older, and it may therefore be objected that the peculiar features of mortality only arise from this circumstance. If we, however, calculate the number of deaths expected during each year of age according to the above-named rates, supposing 10.37 per cent. to die in the first 4 quarters, 11.20 in the next, and so on, we shall find the following result:-

\begin{tabular}{|c|c|c|c|c|}
\hline \multirow{2}{*}{\multicolumn{2}{|c|}{ Age. }} & & \multicolumn{2}{|c|}{ Number of } \\
\hline & & & $\begin{array}{l}\text { Actual } \\
\text { deaths. }\end{array}$ & $\begin{array}{l}\text { Expected } \\
\text { deaths. }\end{array}$ \\
\hline $95-96$ & lusive) & & 77 & $77 \cdot 5$ \\
\hline $97-98$ & , & $\ldots \ldots \ldots \ldots \ldots \ldots$ & 85 & $81 \cdot 3$ \\
\hline $90-100$ & , & $\ldots \ldots \ldots \ldots \ldots \ldots$ & 50 & $45 \cdot 5$ \\
\hline 101 and al & & & 17 & $24 \cdot 8$ \\
\hline
\end{tabular}

There is no marked difference between the actual and expected numbers; and there is evidently more probability that mortality after 101 is smaller than in younger ages, than for the opposite theory. What has been observed above thus holds good if we take the various aspects of the year in consideration. On the whole these 5 years have been favourable to the old persons, for at the close of the period of observation there were 2-3 times as many persons above 100 as before It is not uncommon to observe interruptions like this in the general law of increasing mortality according to age. Mr. A. N. Kjœr, Director of the Norwegian Bureau of Statistics, points out a remarkable connection between mortality and marriages, in the ages $22-32$ years. During this period of life the greater part 
of the male population enters marriage with its generally healthy influence on the chances of life. According to the unadjusted Norwegian life-table the rates of mortality of males are, during these 10 years constantly decreasing from 9.3 per $\mathrm{m}$. to 7.9 per $\mathrm{m}$. But at the same period of life we shall find that mortality of bachelors is on the whole increasing, of married men likewise, or at least not essentially decreasing. The fact that there is a constant stream from the comparatively unhealthy class of bachelors to the more settled class of married men with their smaller rates of mortality, explains the considerable reduction of mortality in this period of life.

A similar interruption of the increase of mortality may be observed among persons with a consumptive family history after the age of about 40 years. Another striking fact is the mortality of retired civil or military officers, or on the total of persons retiring on account of age or debility from their usual activity. In a report on the pensions of the Danish clergy, I have pointed out a curious influence of the time elapsed since the retirement. On an average, Danish clergymen retire when 69 years old; on the whole we should presuppose that mortality would be increasing with the distance in time since retiring, though not in the same degree as according to a common life table, as some of the retiring clergymen are comparatively young with greater chances of surviving, whereas others are very aged, and may soon be expected to die out.

But if we group the observations according to the time elapsed since retiring we shall find the following numbers (1857-85).

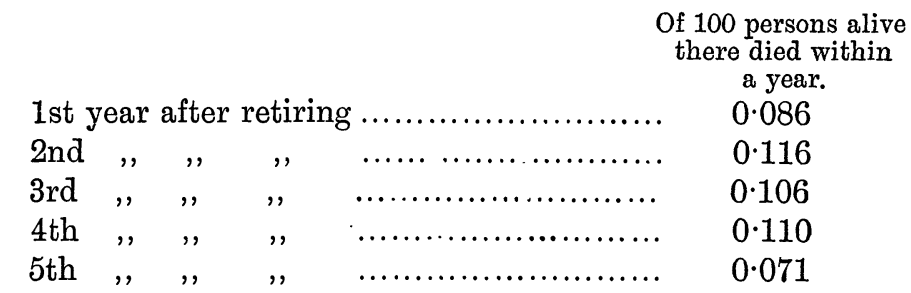

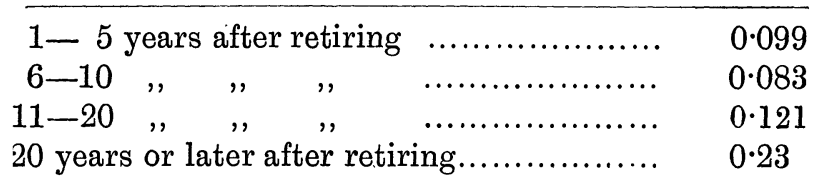

Altogether.

0.099

From the first year with its rather exceptional conditions to the second one, there is thus a considerable increase of mortality, but afterwards the chances of life are improving (or at least they do not get worse) with the advancing age, till a minimum is reached after $4-5$ years. On the whole there died, proportionately, more during the first 5 years than during the next quinquennium, but after that time considerable increase can be observed. 
There are thus strong causes in action counterbalancing the general increase of mortality with advancing years, and several of these causes may be easily pointed out. Evidently there is a sort of selection going on; the clergymen with failing health retire, whereas the comparatively youthful remain at work; but after a while many of those who gave up their work on account of illness have died out, and the remainder lead a quiet vegetative life, without much excitement and with hardly any strain on their small bodily and mental strength. No wonder then that they may continue this quiet life for many years, till at last some illness overtakes them.

A similar selection is probably going on in all classes of population. There is a period of life when almost all who attain it are forced to be inactive ; at first this change is serious enough, but gradually an aged person grows' accustomed to it and now he leads a quiet life with very few necessaries, very seldom affected by anxieties which may darken the horizon of younger men, often taking only a small notice of events which would have afflicted him seriously 20 or 30 years ago. Life goes on calmly like a quiet brook, till at last it is interrupted in some way or other, and death comes with hardly any agonies. Moreover, human beings evidently grow old at very different ages. Some are youthful and vigorous at 80 , others are in a state of decay at 60 . I thus return to the argument I used above with regard to errors of the census. Every life-table is, in fact, a combination of a great many tables. Taking the population as a totality we have the various professions, the frugal and the drunkard, the bachelor and the married, the country and the city life, and so on. And even if we single out a distinct class it will always hold an infinite number of varieties, of which the life table is a combined result. A thousand old men of ninety are perhaps to be separated in several classes each with its own vitality differing more or less from the average, some of them to be compared to 'men of 70 or 80 , whereas others have very few chances of life. This may explain the curious bending at extreme old age of the mortality curve, and the fact that a few persons now and then reach an astonishing age like Drakenberg or others. Exactly the corresponding remark may be made on younger ages, but the consequence will not be the same. Taking for instance 50 males 60 years old and 50 of 80 years, we shall according to the Norwegian adjusted life-table find about 43 persons alive after 10 years, whereas of 100 of 70 years about 46 will be alive, the latter number being thus somewhat greater than the former. But trying the same with persons 10 years older we shall find 27 alive out of the two groups originally of 70 and 90 years of age, but only 16 of 100 aged 80; the deviation is now much greater and there will now be many more alive of the two groups combined than of the more uniform group. The same will take place with all higher ages.

What I have here propounded is, of course, open to objections, the most important one being probably that many more facts will be

No. 34.- -VOL. IX. 
necessary if a trustworthy life-table for aged persons is to be computed. I quite agree with this, and if the Norwegian list of observations and my remarks thereon should stimulate other bureaus of statistics to investigate this interesting problem it would be a great service to the science of statistics. Such observations will contribute to the solution of a problem which has hitherto been to a great extent unsolved, that of ascertaining the degree of accuracy of statistical data. In physics and astronomy this problem is most carefully treated, but it is very rare to meet such investigations in the sphere of official or private statistics; most statisticians being content with the consciousness of having made their observations as correctly as possible, but rarely asking how great the errors of observations actually are.

Harald Westergaard

\section{The Economic Aspect of Australian Federation.}

"The channel forbids union, the ocean forbids separation," was a statement once made by Grattan, which was full of meaning at the time of its utterance. Of Australia we may say on the contrary, "The ocean entails continental isolation; but no natural barriers exist to prevent a federal union." The celebration in 1888 of the centenary of Australian colonisation by the British race was productive of a wave of true national, as distinct from purely colonial feeling and sentiment, which has continuously increased in volume and force until throughout the continent to-day the cry of "Australians as one people," has become irresistible alike to people and politicians, to press and priesthood. By evolutionary stages, from vague sentiment in past years to the first constitutional essay of 1891, and from the Convention Bill of seven years ago to the Commonwealth Bill of 1898 -in favour of the adoption of which 219,000 persons voted in four colonies, whilst 108,000 persons voted in opposition, principally in New South Wales-the federal spirit has made a way for itself, and has penetrated every channel of domestic, commercial and political activity. In New South Wales, at the last general election, the candidates seeking the suffrages of the electors, unanimously declared in favour of Federation on "safe and just lines," and the Parliament elected is pledged to give effect to the wishes of the constituencies. The feeling in favour of Federation is overwhelming, but just as the Commonwealth Bill of 1891 issued still-born from the printing press, doomed by lack of financial skill and foresight, and by the weakness of its provisions for economical self-government, so the Commonwealth Bill of 1898 has been rendered obnoxious to important sections constituting influential minorities in each colony concerned, by reason of the fact that although in many respects "the freest constitution on record" has been framed, in other directions there are provisions 